\title{
O Museu do Barro da UFSJ e o resgate da cerâmica Quilombola de Palmital e Jaguara
}

\author{
The clay museum of UFS and the recovering of the Palmital and Jaguara \\ Quilombola ceramics
}

\author{
Lilian Góis ${ }^{1}$, Vítor Augusto do Nascimento ${ }^{2}$, Isis Bey Trindade ${ }^{3}$, Zandra Coelho de Miranda ${ }^{4}$ \\ 1 Graduanda. Universidade Federal de São João del Rei (UFSJ), Brasil. E-mail: ligois84@gmail.com \\ 2 Graduando. Universidade Federal de São João del Rei (UFSJ), Brasil. E-mail: vitornascimento50@gmail.com \\ 3 Graduanda. Universidade Federal de São João del Rei (UFSJ), Brasil. E-mail: beytrindade@gmail.com \\ 4 Professora adjunta. Universidade Federal de São João del Rei (UFSJ), Brasil. E-mail: zandra.coelho@gmail.com
}

Recebido em: 31/03/2015 | Aprovado em: 29/08/2015

DOI: 10.12957/interag.2016.23574

\begin{abstract}
Resumo
Este relato se refere ao Programa de Extensão Museu do Barro da Universidade Federal de São João del-Rei (UFSJ), que, em colaboração com o Programa de Extensão Tugu-ná, da mesma Universidade, ampliou o escopo de sua ação em 2014, iniciando uma prospecção de argilas e engobes nos Quilombos de Palmital e Jaquara, com a finalidade de realização de oficinas de cerâmica e de resgate do tradicional fazer cerâmico das Comunidades Quilombola.
\end{abstract}

Palavras-chave: Ceramica, Educação, Identidade.

Área temática: Cultura.

Linha de extensão: Artes Plásticas.

\begin{abstract}
This article refers to the Community Project Clay Museum of the Federal University of São João del Rei (UFSJ), which, in collaboration with the Tugu-ná Community Program, of the same University, widened its range of action in 2014, starting to prospect clays and engobes in Palmital and Jaguara quilombo communities, with the objective of offering ceramic workshops and the recovery of the traditional ceramic making of the quilombo communities.
\end{abstract}

Keywords: Ceramics, Education, Identity.

\section{Introdução}

O Museu do Barro é um programa de extensão que está em atividade desde 2012, quando se começou a fazer o levantamento do acervo de cerâmicas doado pelo Almirante Max Justo Guedes, juntamente com o imóvel conhecido como Fortim dos Emboabas para a Universidade Federal de São João del-Rei, UFSJ. A equipe do Museu do Barro cresceu após a aprovação da implantação do Centro de Referência da Cultura Popular no Fortim, com verbas aprovadas para o ano de 2013 e com a continuidade do financiamento no projeto aprovado para 2014. Dessa forma, nossa equipe pôde aprofundar as pesquisas sobre o acervo, publicando diversos panfletos e um Catálogo para a divulgação do Museu junto à comunidade acadêmica e ao público em geral. 
Oferecemos, initerruptamente, oficinas à comunidade a partir do Inverno Cultural de 2012, e, com o acervo organizado provisoriamente nos armários existentes no imóvel, chegamos a receber visitantes e manter um plantão para visitas guiadas a pesquisadores, a estudantes, a turistas e à comunidade local.

No final de 2013, o imóvel foi interditado pelo setor de engenharia da UFSJ por estar em risco de desabamento. Foram feitas escoras em alguns pontos da casa e o acesso do público ao imóvel foi proibido. Mesmo assim, utilizando-se da grande tenda colocada no pátio interno, as oficinas foram mantidas, e os saberes e fazeres associados ao acervo continuaram a ser multiplicados com a participação da comunidade sanjoanense em geral e, em especial, a comunidade do Alto das Mercês.

Os temas e processos abordados nas oficinas foram muito diversos, variando desde brinquedos de pano a tapetes de rua, mas priorizamos aqueles temas relacionados ao universo da cerâmica, pois apresentam baixo custo de execução e ainda têm possibilidades de geração de renda em comunidades em vulnerabilidade social. Nesse sentido, foram oferecidas oficinas para ensinar os artesãos do barro a fazer suas próprias ferramentas utilizando materiais de sucata, além de confecção de fornos alternativos para a queima da cerâmica, como o forno de cupinzeiro, ou o forno feito a partir de tijolos comuns, com o objetivo de oferecer certo domínio sobre os meios de produção.

Um dos destaques neste período foi a oficina de Acessórios Cerâmicos, gerando produtos que, depois de ganhar a contribuição de materiais como sementes, madeira e bambu, geraram Biojóias, produzidas durante dois meses, em parceria com o projeto Afromemórias, e com financiamento da Fundação Palmares. Outra oficina de destaque foi a oficina Panelas de Barro, que teve quatro edições em 2014, em que mostramos técnicas de modelagem inspiradas e utilizadas pelas "Paneleiras de Goiabeiras do Espírito Santo". Todas as panelas elaboradas foram queimadas no forno de cupinzeiro.

Tivemos, também, um longo e divertido cronograma para a criançada. Para comemorar a Copa do Mundo, realizamos a oficina de Construção de Tapetes de Rua, no Fortim, além de ensinarmos os alunos da Escola Municipal Maria Tereza a produzir enfeites relacionados à Copa para decorar a escola. 
Na mesma escola, Escola Municipal Maria Tereza, ministramos mais duas oficinas: Construção de Forno de Cupinzeiro e Modelagem em Argila. No período de férias escolares, realizamos a deliciosa oficina de Biscoitos Divertidos e no Dia das Crianças, em que elas se divertiram muito na confecção de seus próprios brinquedos com a oficina Brinquedos de Pano. Para finalizar a programação com as crianças, oferecemos a animada oficina Confecção de Birutas.

Para atender o público adolescente, realizamos a oficina Construção de Máscaras Cênicas para os alunos do $9^{\circ}$ ano da Escola Municipal CAIC. Os alunos, com muita criatividade, confeccionaram lindas máscaras de gesso e papietagem, que depois foram utilizadas em uma oficina de teatro (Fig.1). A retrospectiva completa e detalhada das atividades do Museu do Barro pode ser consultada através do link: https://www.facebook.com/museudobarroufsj

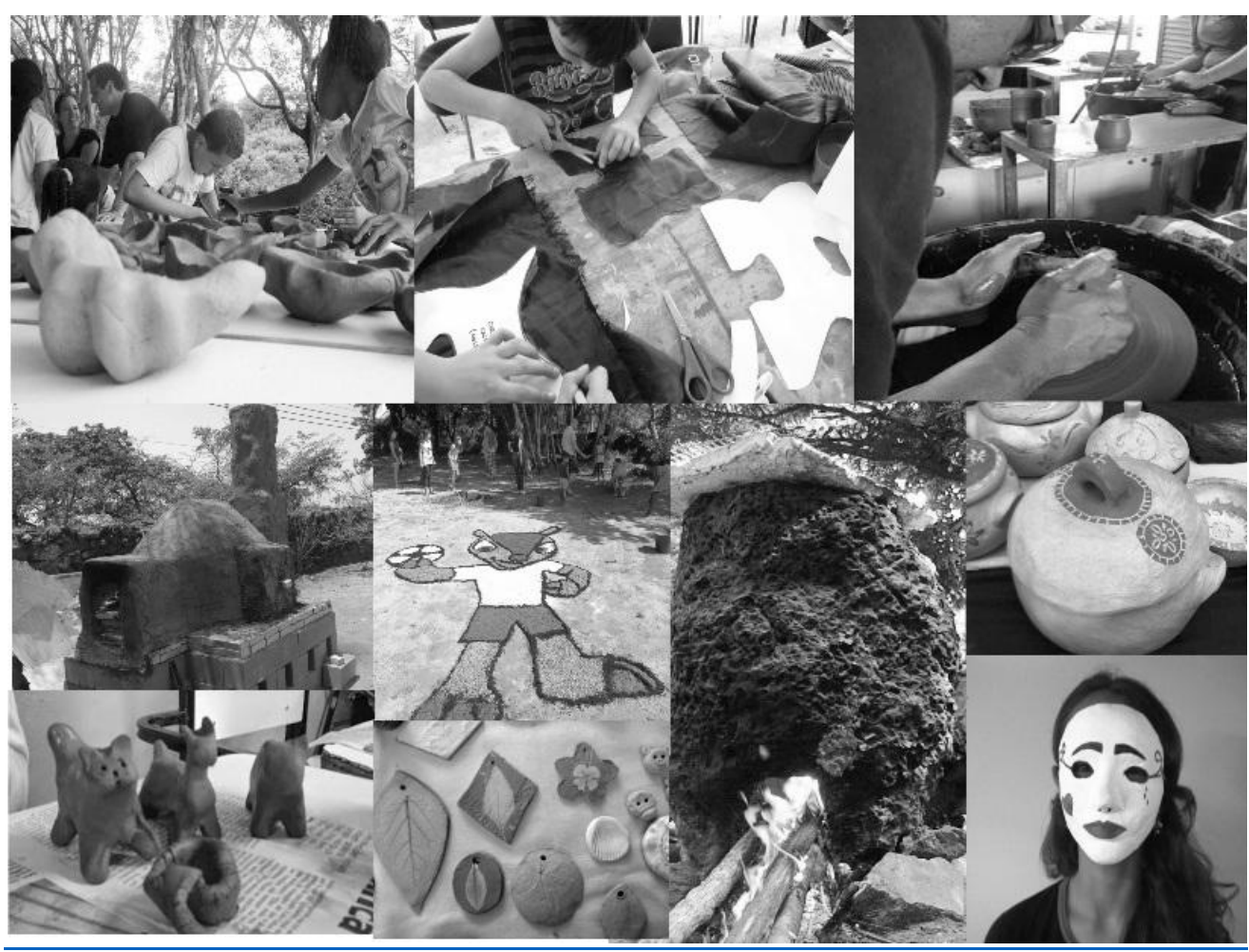

Figura 1. Momentos selecionados das oficinas realizadas pelo programa entre marco de 2014 e marco de 2015. Fotos da equipe do Museu do Barro, montagem de Lilian Góis.

A repercussão dos trabalhos realizados acabou gerando um convite do coordenador do 
Programa de Extensão Tugu-na para que fizéssemos uma visita aos Quilombos de Palmital e Jaguara, localizados próximo ao município de Nazareno a $50 \mathrm{~km}$ de São João del Rei. Desde 2003, o programa História e Cultura Africana e Afro-Brasileira junto com o Grupo de Estudos Tugu-na, coordenados pelo Professor Doutor Manuel Jauará, do Departamento de Ciências Sociais (DECIS) da Universidade Federal de São João del-Rei (UFSJ), desenvolve ações de extensão nas comunidades remanescentes quilombolas Jaguara e Palmital, em Nazareno.

Os trabalhos desenvolvidos pelo grupo Tugu-na abrangem o resgate da documentação e a coleta de história oral para a efetivação dos registros cabíveis com o objetivo de obtenção de personalidade jurídica, dando assistência para que as comunidades sejam reconhecidas legalmente, assegurando a preservação dos valores culturais e do patrimônio material e imaterial das comunidades. Por outro lado, também buscam consolidar a formação e a organização funcional da Associação dos Moradores das comunidades de Jaguara e Palmital.

No final de 2013, a partir de documentos entregues para a Fundação Palmares, órgão do Ministério da Cultura, foi publicado no Diário da União o reconhecimento dessas duas comunidades como sendo oficialmente Comunidades Quilombolas e foi emitido um certificado, que o grupo Tugu-na formalmente entregou em uma solenidade convocada para essa finalidade. Este documento permite à comunidade pleitear diretamente recursos ao Município, ao Estado ou ao próprio Governo Federal, além de possuir o direito de requerer, junto ao INCRA, a demarcação formal das terras Quilombolas, que as tornam invioláveis e ainda impede qualquer tentativa de apropriação ou usurpação ilegal.

A partir desse contexto, pensando na importância do resgate cultural dessas comunidades e em uma possibilidade de gerar renda para as Comunidades Quilombolas, e tendo como objetivo trabalhar as técnicas da cerâmica em Jaguara e Palmital, iniciamos uma parceria. Com a parceria, verificou-se a alta vulnerabilidade social nestas comunidades, sendo levantado que a fonte de renda principal vem da colheita esporádica de café nas fazendas circunvizinhas. Durante uma visita à Jaguara, 
o morador e líder da comunidade, Sr. João, informou que naquelas localidades já foram encontrados cacos e restos de cerâmica antiga e que, outrora, fabricavam tijolos de adobe para a construção das primeiras casas na comunidade. Ele nos orientou na busca pelas amostras de barro e nos levou a um local chamado de "bica", localizado atrás de uma igreja, de onde era retirado o barro para se fazer o adobe. Nesse local, amostras de terras e argilas foram recolhidas para a realização de testes em que foram verificados a retração, a plasticidade, a sinterização e a coloração do barro, no Laboratório Escola de Cerâmica da UFSJ, como nas figuras 02 e 03.
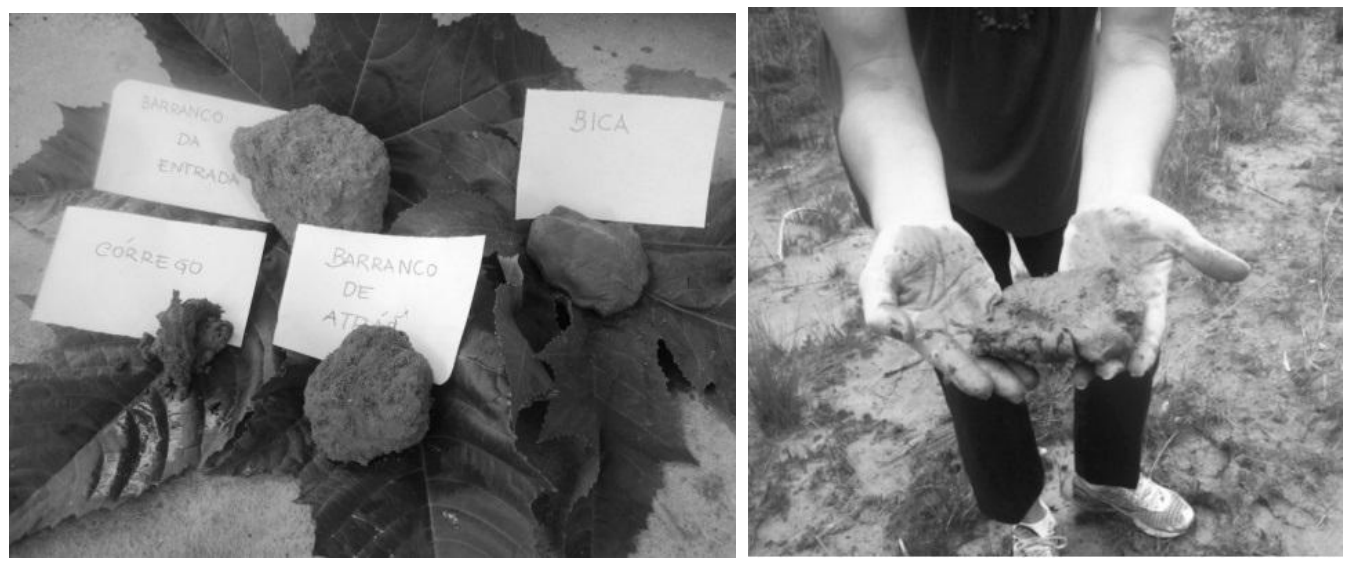

Figuras 2 e 3. Amostras de barro encontrados na Comunidade Jaguara. Fotos da equipe do Museu do Barro, realizadas em agosto de 2014.

Em Palmital,foi constatado um grande potencial para o desenvolvimento de engobes, que são tintas elaboradas com terras e óxidos, pois seu solo é riquíssimo e possui uma grande diversidade de cores. Também foram identificados cupinzeiros adequados para a construção de fornos alternativos, tornando a produção cerâmica viável e acessível às comunidades. Na mesma ocasião coletamos amostras para testes e realizamos inscrições para as oficinas, e o público, de faixa etária diversa, se mostrou bastante interessado, figuras 04 e 05. 


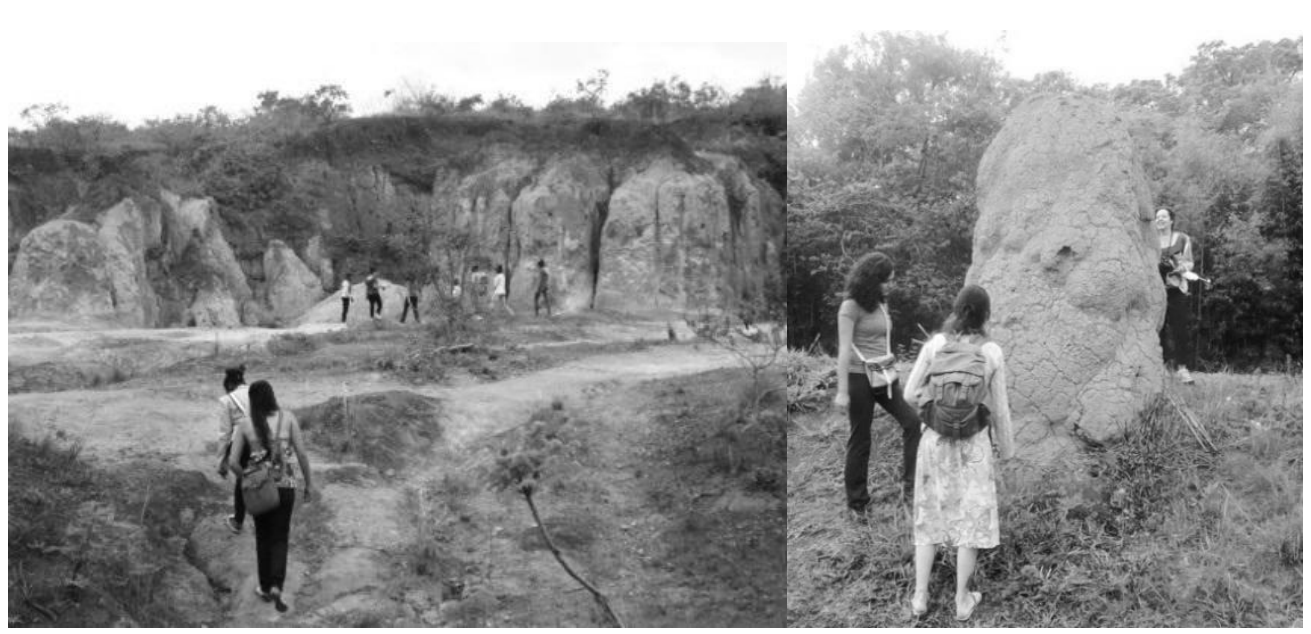

Figuras 4 e 5. Voçoroca localizada na Comunidade Palmital e um dos diversos cupinzeiros adequados para a construção de um forno para queima de cerâmica, existentes em Jaguara. Fotos da equipe do Museu do Barro, realizadas em agosto de 2014.

Após as visitas de prospecção, no laboratório de cerâmica da UFSJ, realizamos testes com as argilas coletadas nas duas comunidades, observando a plasticidade e a retração, mas nenhuma se apresentou apropriada para iniciar as atividades, por apresentarem pouca plasticidade e muita fragilidade após a queima das argilas. Já com as amostras das terras coletadas, conseguimos uma variedade de cores e preparamos os engobes, que serão utilizados nas oficinas para as pinturas das peças cerâmicas, figuras 06, 07 e 08.
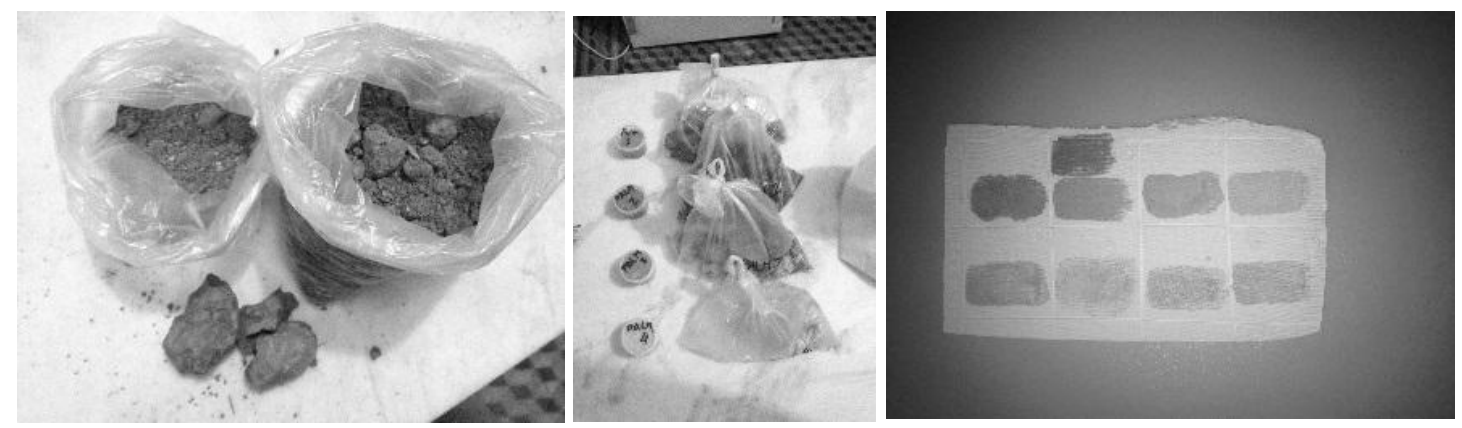

Figuras 6, 7 e 8. Terras coletadas e queimadas, em que a argila de Jaguara demonstrou-se porosa e quebradiça. As amostras utilizadas para formular engobes, ou tintas à base de terra, geraram excelentes amostras, que foram utilizadas nas oficinas subsequentes. Fotos da equipe do Museu do Barro, realizadas em outubro de 2014.

Na segunda visita à comunidade de Palmital, os testes foram apresentados e iniciamos as atividades mostrando algumas técnicas simples de modelagem com argila em que os participantes puderam confeccionar alguns acessórios e utilitários. Usando diversas técnicas, como anelamento, belisque e placas, os participantes fizeram canecas, diversas 
miçangas, amuletos, medalhões, acessórios, carimbos, entre outros. Neste momento, houve bastante interação do grupo tendo produzido uma quantidade significativa de peças que foram colocadas em bancadas para então proceder à secagem.

Posteriormente, fomos com o grupo até a voçoroca, onde encontramos e coletamos diversas cores de terras para a confecção das tintas, conhecidas como engobes. E então mostramos aos participantes o passo a passo na produção dos engobes, bem como disponibilizamos o material aos participantes para pintarem seus trabalhos. Ao encerrar a oficina, guardamos as peças produzidas, os engobes e as ferramentas na própria varanda da casa.

Durante este encontro, um morador da comunidade levou um saco com uma amostra de argila que havia coletado em um lago da comunidade, onde as crianças brincam e nadam. Em uma análise inicial feita pelo grupo, observamos que a argila encontrada era de cor branca e com plasticidade, possivelmente, uma argila de boa qualidade. Essa descoberta gerou grandes expectativas de possuir uma fonte boa de argila na comunidade e, então, levamos essa amostra para uma análise mais detalhada em laboratório. Os resultados foram surpreendentes. A massa mostrou-se bastante adequada para a realização das propostas. Além de grande plasticidade, a argila apresentou-se com uma boa sinterização, sendo bastante resistente depois da queima e com um baixo nível de retração. A coloração branca permaneceu, mostrando-se muito propícia para a aplicação de engobes e esmaltes, além da possibilidade de ser uma das características marcantes da cerâmica desenvolvida na região, agregando grande valor artístico e comercial, Fig. 09. 


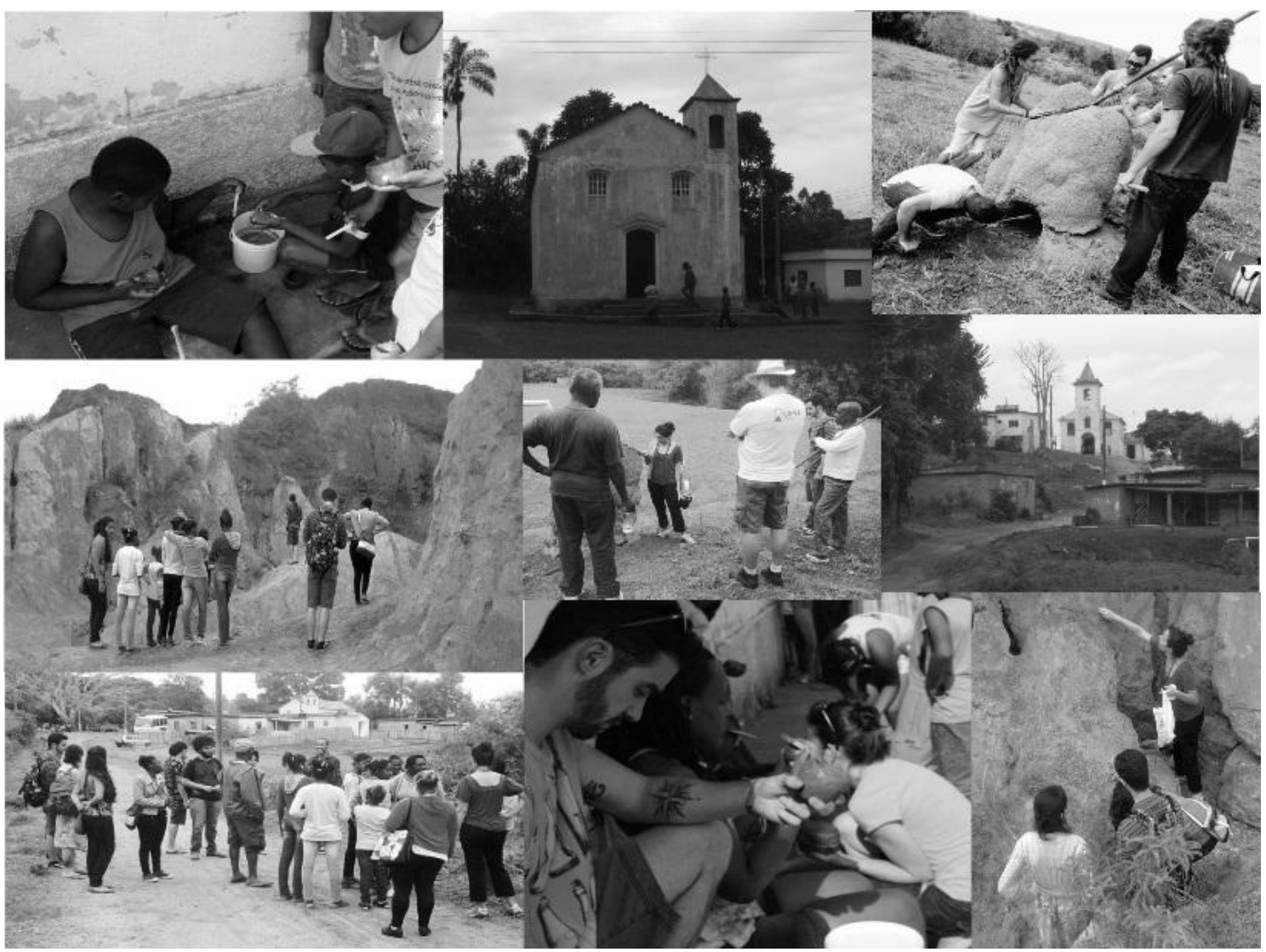

Figura 9. Momentos selecionados das oficinas realizadas pelo programa nos quilombos de Palmital e Jaguara ente agosto de 2014 e março de 2015. Fotos da equipe do Museu do Barro, montagem de Lilian Góis.

No último encontro de 2014, as atividades de modelagem foram retomadas e os participantes foram estimulados à produção de peças maiores, como panelas, canecas e vasos. A produção foi bastante satisfatória e novamente essas peças foram levadas para queima no forno do Laboratório da Escola de Cerâmica da UFSJ.

Os participantes se mostraram animados com o resultado de suas peças queimadas e receberam materiais para desenvolverem novos trabalhos no período de recesso, sendo que a construção do forno de cupinzeiro foi marcada para o início do semestre seguinte.

Durante todo o processo de parceria com as Comunidades, buscamos analisar e discutir as dificuldades encontradas. Nesse processo, algumas ações foram propostas para o semestre seguinte, 2015/01, como a construção de um galpão construído com baixo custo, utilizando materiais como adobe e outros. 
Contando com a ajuda dos moradores das Comunidades, a intenção é adquirir um espaço adequado para a realização das atividades que possa criar na comunidade um sentimento de pertencimento e autonomia. Também foram discutidas as metodologias possíveis de serem aplicadas e a necessidade de maior interação com outras atividades desenvolvidas por outros núcleos do Grupo Transdisciplinar de Pesquisa em Arte e Sustentabilidade - GTPAS nas comunidades.

Com o auxílio de material teórico, foram analisadas e comparadas as práticas cerâmicas desenvolvidas nas seguintes comunidades quilombolas: Comunidade da Olaria, IraráBahia $^{1}$, e Comunidade da Região de Porto Trombetas - Pará, através do documentário "Filhos do Barro"2, relacionando e comparando as características e semelhanças com as comunidades quilombolas de Palmital e Jaguara, em Minas Gerais.

Antes de analisarmos a produção cerâmica dessas comunidades, foi observada a semelhança entre os contextos de alta vulnerabilidade social e verificado que, em diferentes níveis, as comunidades analisadas enfrentam as mesmas dificuldades de acesso à educação, saúde, transporte e outros fatores limitantes que reduzem e dificultam a compreensão dessas comunidades sobre suas raízes, valores e saberes. Consequentemente, por parte dos próprios integrantes, há uma baixa autoestima, gerando preconceito para com sua própria cultura, e desta forma, uma desvalorização dos saberes da comunidade.

De certa forma, essa desvalorização da comunidade também pode inviabilizar a continuidade dessas atividades próprias de sua cultura, já que as gerações mais jovens não possuem interesse em tal aprendizado. Para exemplificar, mencionamos aqui a fala de uma integrante da comunidade da Olaria, em Irará-BA , Elza Santos, que diz:

"Aqui o povo diz que fazer cerâmica é coisa de nego, por isso que ninguém quer fazer. $\mathrm{O}$ povo mais velho que fazia, mas agora o povo mais jovem não quer se sujar fazendo panela, não! ".

Tal fala de Santos reflete a realidade dessas comunidades, onde a tradição ceramista está ameaçada de extinção.

Outra característica presente nessas comunidades é o fato do saber cerâmico ser 
predominantemente dominado pelo gênero feminino. Uma tradição passada de mãe para filha, ou de sogra para nora. Focando nessa característica, observamos que o contexto histórico gerou esse domínio feminino na atividade ceramista. Os relatos das mulheres mais velhas mencionam que as meninas desde cedo eram estimuladas a substituir as brincadeiras pela realização de atividades domésticas, tarefas como cozinhar, lavar, cuidar dos irmãos menores ou limpar a casa.

Nesse contexto feminino, também aprendiam a modelar o barro e realizar queimas, pois a retirada do barro é realizada exclusivamente por mulheres. Na comunidade de Porto Trombetas $/ \mathrm{PA}^{2}$, as mulheres fazem um ritual, onde pedem licença para a retirada do barro e, em tal ocasião, elas cantam e, posteriormente, como oferenda de gratidão, deixam no local uma panela. Essa tradição se assemelha à de diversas comunidades indígenas, onde é visível o respeito com a terra, a "Mãe natureza". Essa é uma dentre outras características que nos fazem especular acerca das origens e interações da produção cerâmica quilombola, de origem africana e indígena.

As queimas também são de responsabilidade das mulheres, cujo hábito reproduz o cotidiano feminino que se volta para o cozimento de alimentos. Basicamente, as mulheres realizam todo o processo da produção cerâmica, pois os homens saem do convívio familiar em busca de trabalho em outras propriedades vizinhas, recebendo baixíssimos salários com a produção agrícola. Esse trabalho é conhecido como a tarefa de ganhar o dia, e, uma vez que os homens, em geral, não têm a quem vender o dia, perdem o dia sem trabalhar e, portanto, não ganham nenhum dinheiro.

Frente a essa difícil situação social, evidencia-se a importância da atividade cerâmica visando a geração de trabalho e renda, centrando o foco nas determinações de sua existência social envolvendo produção, distribuição e comercialização e vislumbrandose assim na produção cerâmica uma alternativa de sobrevivência.

Nessa nova realidade, sendo o ganho obtido por mulheres maior do que o obtido pelos homens, observamos que, tal aumento na renda familiar possibilita ainda às mulheres que revejam seu papel social. Uma vez que sua posição econômica é ativa, promove-se então a valorização do papel do feminino em uma sociedade tradicionalmente dominada por homens. 
Além disso, este é um saber que não se consolida em uma atividade puramente individual, pois a técnica e o saber são compartilhados pelo grupo, criando uma forte relação de identificação e solidariedade. Sabe-se que tal vivência é fundamental para a construção da identidade étnica de um grupo. Nesse processo, há uma revalorização e construção de autoestima da comunidade que passa a reconhecer e afirmar a sua herança cultural, contribuindo para a revitalização de sua identidade étnica.

\section{Referências}

1. SANTOS, Jucélia Bispo dos. Comunidade Relações de Gênero e Produção de Cerâmica na Comunidade Quilobola da Olaria, em Irará-Bahia. Revista Latinoamericana de Geografia e Gênero, Ponta Grossa, v.1, n. 1,p.134-147, jan./jul. 2010. Disponível em: <http://www.revistas2.uepg.br/index.php/rlagg/article/view/1036/812 >.

2. FILHOS DO BARRO: Resultado de ações desenvolvidas junto às populações tradicionais da região. Documentário. 2010. Direção Vitor Lima. 